\title{
MODIFIKASI CABANG OLAHRAGA FUTSAL MENJADI FUTSAL MINI THREE ON THREE
}

\author{
Syawal Febri ${ }^{1}$, Anton Komaini ${ }^{2}$, Andri Gemaini ${ }^{3}$ \\ Jurusan Kesehatan dan Rekreasi, Universitas Negeri Padang, \\ Padang, Indonesia \\ syawalfebri1997@gmail.com
}

\begin{abstract}
There are several problems that form the basis of this research, first, namely; there is often limited player personnel in completing a team to play futsal, second; players find it difficult to issue individual skills to show their skills in playing the ball, even players rarely get touch of the ball so that players feel they have not been maximally processing the ball on the playing field and third; namely the limited infrastructure in the form of a playing field. The objectives to be achieved in this study are to overcome the above problems by modifying the futsal sport into a three on three mini futsal. In this type of RND (Research and Development) research, there are 10 steps that must be passed, but in this study only six steps are used, namely from potential problems, data collection, product design, design validation, design revision, and product testing. The modification of the futsal sport into a mini three on three futsal was validated by three futsal experts and tested with a sample of 12 people. Based on the research results, the modification of futsal into three on three mini futsal is categorized as "Very Good / Feasible" as a new game called futsal mini three on expert got the Very Good / Decent category $90.37 \%$, two futsal experts were Good / Decent $80 \%$, and three futsal experts were Very Good / Decent $96.29 \%$. Therefore, the conclusion of this research is that the mini three on three futsal game is very feasible and can be played by all parties.
\end{abstract}

\section{Keywords: Futsal, Futsal Mini Three on Three}

\section{Abstrak}

Terdapat beberapa permasalahan yang menjadi landasan dalam penelitian ini pertama yaitu; seringnya terjadi keterbatasan personil pemain dalam melengkapi sebuah tim untuk memainkan futsal, kedua; pemain sulit mengeluarkan skil individu untuk memperlihatkan keahliannya dalam memainkan bola, bahkan pemain juga jarang mendapatkan sentuhan bola sehingga pemain merasa belum maksimal mengolah bola di dalam lapangan permainan dan katiga; yaitu keterbatasan prasarana berupa lapangan permainan. Tujuan yang hendak dicapai dalam penelitian ini adalah mengatasi masalah-masalah di atas dengan memodifikasi olahraga futsal menjadi futsal mini three on three.

Dalam jenis penelitian RND (Research and Development) terdapat 10 langkah yang harus dilewati, namun dalam penelitian ini hanya menggunakan enam langkah yaitu dari potensi masalah, pengumpulkan data, desain produk, validasi desain, revisi desain, dan uji coba produk. Modifikasi cabang olahraga futsal menjadi furtsal mini three on three ini divalidasi oleh tiga ahli futsal dan diuji cobakan dengan sampel sebanyak 12 orang.

Berdasarkan hasil penelitian modifikasi cabang olahraga futsal menjadi futsal mini 
E-ISSN2655-2515

P-ISSN2655-1802

three on three ini dikategorikan "Sangat Baik/Layak" sebagai sebuah permainan baru bernama futsal mini three on three. Hasil tersebut diperoleh dari tiga ahli futsal, yang mana ahli futsal satu mendapatkan kategori Sangat Baik/Layak $90,37 \%$, ahli futsal dua Baik/Layak $80 \%$, dan ahli futsal tiga Sangat Baik/Layak $96,29 \%$. Dengan demikian kesimpulan dari penelitian ini permainan futsal mini three on three sangat layak dan bisa dimainkan oleh segala pihak.

\section{Kata kunci: Futsal, Futsal Mini Three on Three}

\section{Pendahuluan}

Olahraga merupakan suatu kegiatan fisik yang dilakukan dengan terstruktur, terprogram, dan berkelanjutan.Dengan berolahraga dapat meningkatkan kebugaran jasmani.Kegiatan olahraga adalah kegiatan yang sangat banyak digemari masyarakat dikarenakan selain bertujuan meningkatkan kebugaran, berolahraga juga dapat menimbulkan kesenangan tersendiri.Banyak masyarakat yang menggemari aktifitas fisik ini dikarenakan suatu kegiatan yang bermanfaat sekaligus menjadi banyak dijadikan sebagai hobi bagi masyarakat Indonesia bahkan sampai mendunia.

Menurut Undang-Undang RI Nomor 3 Tahun 2005 tentang Sistem Keolahragaan Nasional olahraga adalah segala kegiatan yang sistematis untuk mendorong, membina, serta mengembangkan potensi jasmani, rohani, dan sosial. "Olahraga adalah kegiatan aktivitas jasmani yang mengandung sifat permainan serta berisi perjuangan dengan diri sendiri, orang lain, dan alam yang mempunyai tujuan tertentu" (Setiyawan, 2017:78)

Dalam Undang-Undang RI No. 3 tahun 2005 sistem keolahragaan nasional mengenai pembinaan dan pengembangan olahraga yang terdapat pada pasal 21 sampai 24 menjelaskan yang dapat disimpulkan :

1. Pembinaan dan pengembangan olahraga meliputi pengolahragaan, ketenagaan, pengorganisasian, pendanaan, metode, prasarana dan sarana, serta penghargaan keolahragaan.

2. Pembinaan dan pengembangan keolahragaan dilaksanakan melalui tahap pengenalan olahraga, pemantauan, pemanduan, serta pengembangan bakat dan peningkatan prestasi.

3. Masyarakat dapat melakukan pembinaan dan pengembangan olahraga melalui berbagai kegiatan keolahragaan secara aktif, baik yang dilaksanakan atas dorongan Pemerintah dan/atau pemerintah daerah, maupun atas 
kesadaran atau prakarsa sendiri.

Maka dari itu pembinaan dan pengembangan olahraga sangat diperlukan bertujuan terjadinya peningkatan presatasi atlet serta tercapainya dasar terbentuknya undang-undang tersebut yaitu meningkatkan kualitas hidup manusia Indonesia secara jasmaniah, rohaniah, sosial dalam mewujudkan masyarakat yang adil, jujur, makmur, sejahtera dan demokratis berdasarkan Pancasila dan UndangUndang Dasar Negara Republik Indonesia Tahun 1945.

Terkait dengan itu terdapat beberapa cabang olahraga yang perkembangannya begitu pesat, hal ini dikarenakan cabang olahraga tersebut merupakan cabang olahraga permainan yang menimbulkan rasa kesenangan bagi masyarakat yang memainkannya.Cabang olahraga tersebut merupakan futsal, basket, sepakbola dan cabang olahraga permainan lainnya.Seperti olahraga futsal yang saat ini sedang marak dimainkan oleh masyarakat Indonesia.Hal ini adalah salah satu bentuk dari perkembangan olahraga nasional. Futsal merupakan permainan bola yang dimainkan oleh dua regu, yang masing-masing regu beranggotakan lima orang. Tujuannya adalah mamasukan bola ke gawang lawan, memanipulasi bola dengan kaki dan anggota tubuh lain selain tangan, kecuali posisi kiper. Selain lima pemain utama, setiap regu juga diizinkan memiliki pemain cadangan.

Futsal adalah salah satu cabang olahraga permainan yang perkembangannya cukup pesat di Indonesia baik di kota-kota maupun di perdesaan.Salah satu yang membuat permainan futsal menarik dilakukan dikarenakan lapangannya yang kecil dan tensi permainan yang tinggi sehingga menimbulkan tantangan tersendiri bagi pemain untuk memainkan futsal.Selaras dengan pendapat Narlan, Juniar, dkk (2017:242) "salah satu kelebihan permainaan futsal adalah dengan ukuran lapangan yang kecil sehingga tidak membutuhkan lahan yang sangat luas seperti lapangan sepakbola".Rahmanda dan Komaini (2018:146) mengutarakan "futsal dipandang sebagai olahraga prestasi yang telah banyak mendapatkan perhatian relatif besar dari masyarakat, hal ini dibuktikan dengan adanya dukungan terbesar dalam bentuk wadah-wadah program pembinaan atlet usia dini oleh akademiakademi futsal di setiap kota dan kabupaten".Akan tetapi ada beberapa hal yang manghambat masyarakat melakukan olahraga futsal yaitu keterbatasan prasarana berupa lapangan permainan.

Selain itu hal yang sering ditemukan dalam permainan futsal yaitu para pemain sulit mengeluarkan skil individu untuk memperlihatkan keahliannya dalam 
memainkan bola, bahkan pemain juga jarang mendapatkan sentuhan bola sehingga pemain merasa belum maksimal mengolah bola di dalam lapangan permainan. Tak lepas dari permasalahan tersebut, hal yang sering menjadi penghambat masyarakat dalam bermain futsal yaitu keterbatasan personil pemain dalam melengkapi sebuah tim untuk memainkan futsal. "Futsal dimainkan oleh dua tim. Jumlah pemain setiap tim maksimal lima orang, dengan salah satunya adalah penjaga gawang. Jumlah pemain cadangan maksimal sebanyak tujuh orang" Sutanto (2019:133). Dikarnakan hal tersebut sering terjadi kekurangan personil tim dalam memainkan futsal. Tidak tercukupimya lima pemain dalam satu tim membuat masyarakat menjadi malas bermain futsal. Maka dari latar belakang yang telah dipaparkan di atas peneliti akan mengambil judul Modifikasi Cabang Olahraga Futsal Menjadi Futsal Mini Three on Three.

\section{Metode}

Penelitian ini menggunakan metode penelitian dan pengembangan (R\&D). Metode Research and Development adalah sebuah metode penelitian yang digunakan untuk menghasilkan produk tertentu, dan menguji keefektifan produk tersebut Sugiyono (2012: 333). Penelitian ini betujuan memodifikasi sebuah cabang olahraga futsal dengan mengubah sistem pertandingan, sarana maupun prasarana perrmainan tersebut. Maka dari itu produk yang dihasilkan dan diuji keefektifan dalam pennelitian ini berupa sebuah cabang olahraga baru yang bernama futsal mini three on three.

\section{Hasil Penelitian}

\section{Validasi Ahli Futsal 1 (satu) bersama Bapak Ridho Bahtra, S.Si., M.Pd.}

Ahli futsal yang menjadi validator pertama pada penelitian dan pengembangan modifikasi cabang olahraga futsal menjadi futsal mini three on three ini adalah Bapak Ridho Bahtra, S.Si., M.Pd. Beliau merupakan salah seorang dosen pada mata kuliah sepakbola dan peneliti yang berkaitan dengan sepakbola di Fakultas IImu Keolahragaan, Universitas Negeri Padang. Beliau juga telah melewati pelatihan pelatih sepakbola D-Licence Nasional di Kabupaten Padang Pariaman Provinsi Sumatera Barat pada tahun 2009, pelatihan Pelatih Futsal Level 1 Nasional di Padang Sumatera Barat pada tahun 2015, dan juga pelatihan Pelatih Futsal Level 1 AFC di Sawangan Depok pada tahun 2015. Validasi ini dilakukan pada tanggal 25 Juli 2020 dengan cara merekam uji coba produk di lapangan, menampilkan cuplikan rekaman ke validator, mendeskripsikan aturan dan cara 
E-ISSN2655-2515

P-ISSN2655-1802

kerja produk disertai instrumen penelitian berupa angket.

Tabel 3. Hasil evaluasi permainan futsal mini three on three oleh ahli futsal 1 (satu).

\begin{tabular}{|c|c|c|c|c|c|c|c|}
\hline No & Aspek & Butir Penilaian & SS & $\mathrm{S}$ & $\mathrm{KS}$ & TS & STS \\
\hline \multirow{8}{*}{$A$} & \multirow{8}{*}{$\begin{array}{l}\text { Kesesuaian } \\
\text { Permainan }\end{array}$} & $\begin{array}{l}\text { 1. Bentuk, skema, dan sistem } \\
\text { permainan sesuai dengan } \\
\text { kaedah-kaedah olahraga } \\
\text { permainan futsal. }\end{array}$ & $\checkmark$ & & & & \\
\hline & & $\begin{array}{l}\text { 2. Permainan bertujuan untuk } \\
\text { meningkatkan keinginan } \\
\text { masyarakat berolahraga. }\end{array}$ & & $\checkmark$ & & & \\
\hline & & $\begin{array}{l}\text { 3. Permainan bertujuan untuk } \\
\text { menyalurkan kemampuan } \\
\text { pemain dalam mengolah bola. }\end{array}$ & & $\checkmark$ & & & \\
\hline & & $\begin{array}{l}\text { 4. Kesamaan tujuan } \\
\text { permainan dengan permainan } \\
\text { futsal biasa yaitu meraih } \\
\text { kemenangan dengan } \\
\text { memasukan bola ke gawang } \\
\text { lawan sebanyak-banyaknya. }\end{array}$ & $\checkmark$ & & & & \\
\hline & & $\begin{array}{l}\text { 5. Permainan dapat dimainkan } \\
\text { oleh segala pihak baik dari } \\
\text { atlet futsal maupu masyarakat } \\
\text { biasa. }\end{array}$ & $\checkmark$ & & & & \\
\hline & & $\begin{array}{l}\text { 6. Sistem dan peraturan } \\
\text { permainan tidak terlalu jauh } \\
\text { berbeda dengan permainan } \\
\text { futsal biasanya. }\end{array}$ & & $\checkmark$ & & & \\
\hline & & $\begin{array}{l}\text { 7. Permainan ini bisa tergolong } \\
\text { pada olahraga prestasi. }\end{array}$ & & & $\checkmark$ & & \\
\hline & & $\begin{array}{l}\text { 8. Permainan ini juga bisa } \\
\text { tergolong pada olahraga } \\
\text { rekreasi atau hiburan. }\end{array}$ & & $\checkmark$ & & & \\
\hline$B$ & $\begin{array}{l}\text { Keefektifan } \\
\text { Permainan }\end{array}$ & $\begin{array}{l}\text { 9. Tidak terlalu banyak } \\
\text { membutuhkan personil untuk } \\
\text { melengkapi jumlah tim. }\end{array}$ & $\checkmark$ & & & & \\
\hline
\end{tabular}




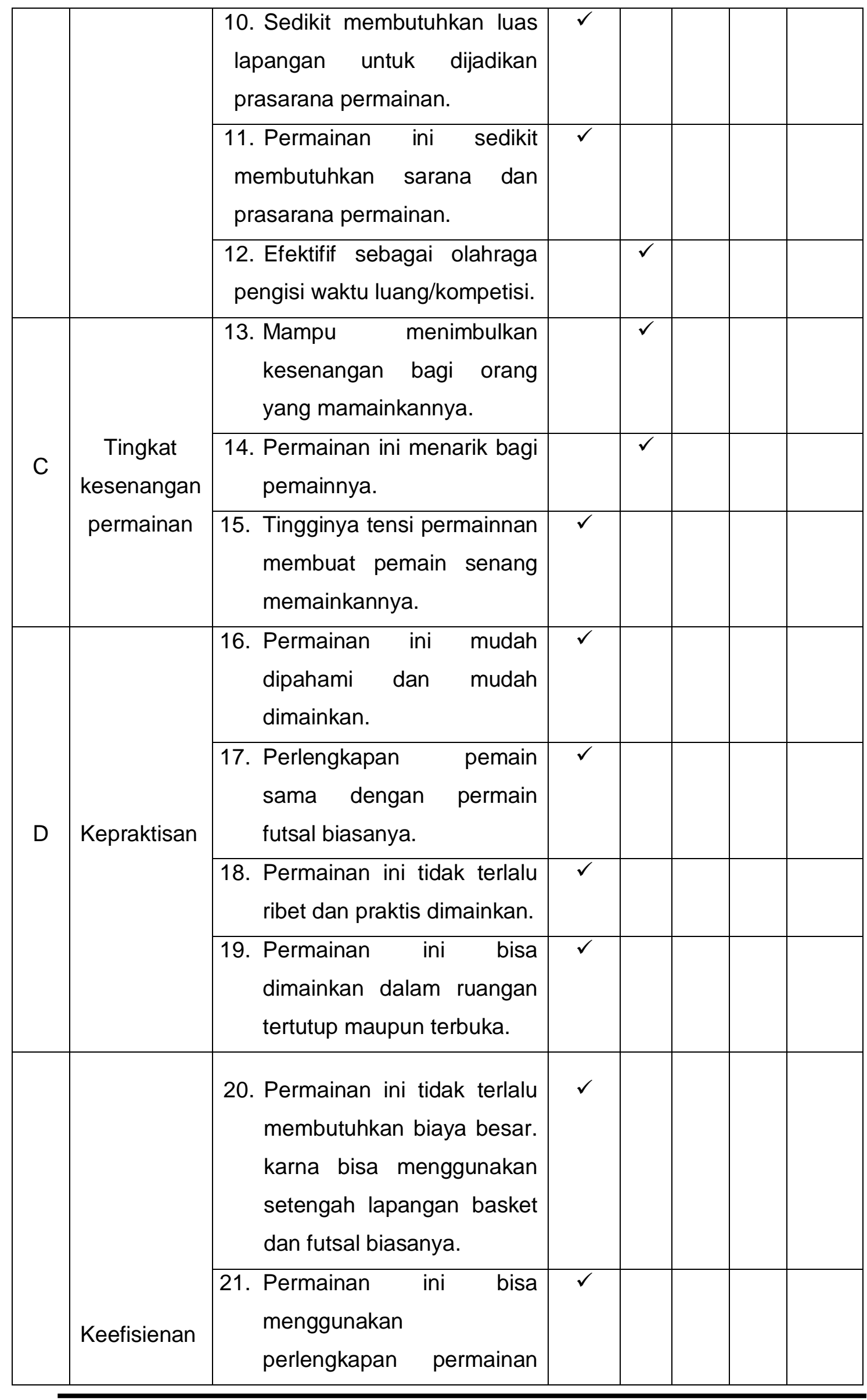




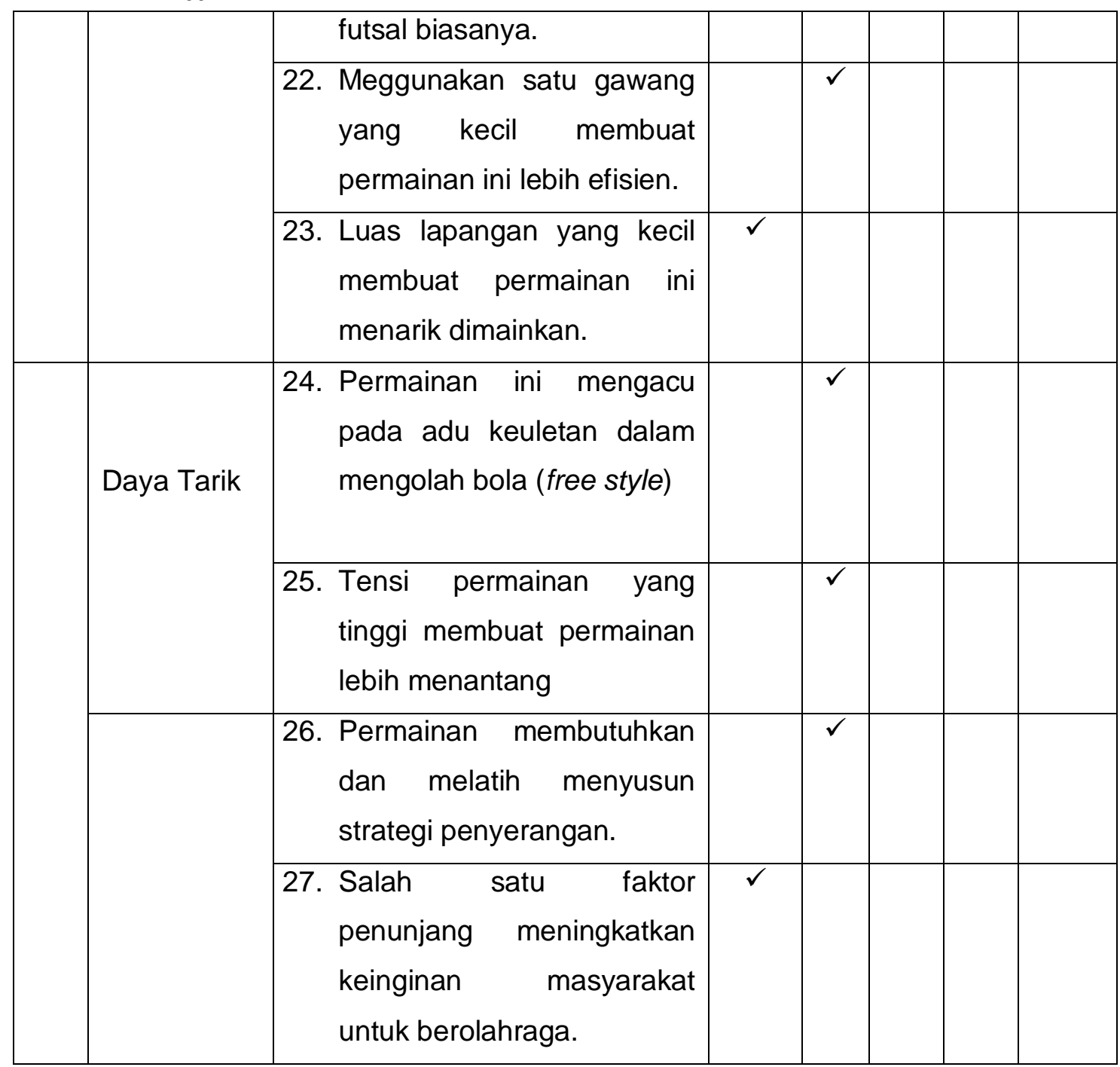

Pada kotak kritik dan saran yang sudah disediakan ahli futsal 1' (satu) mengatakan pengembangan permainan ini sangat bagus dan menarik serta ahli menyarankan untuk menurunkan durasi permainan beserta meningkatkan kuantitas pemain cadangan.

Tabel 4.Persentase hasil penilaian permainan futsal mini three on three

\begin{tabular}{|l|c|c|c|c|c|}
\hline NO & \multicolumn{1}{|c|}{ Ahli } & $f$ & $\mathrm{~N}$ & $(\%)$ & Kategori Kelayakan \\
\hline 1 & Futsal & 122 & 135 & 90,37 & Sangat Baik/Layak \\
\hline
\end{tabular}

Untuk validitas ahli futsal 1 (satu) mendapat persentase penilaian sebesar $90,37 \%$. Maka dari pada itu dapat diartikan permainan futsal mini three on three ini dapat dikategorikan "Sangat Baik/Layak".

Dalam hal ini validator ahli futsal satu memberikan beberapa saran sebagai pertimbangan yaitu sebagai berikut : 
a. Untuk memperpendek durasi bermain yang mana sebelumnya dengan durasi 2x15 menit menjadi 2x10 menit. Hal tersebut dikarenakan tensi permainan terlalu tinggi, jika durasinya terlalu lama akan berdampak atau mengakibatkan pemain beresiko cidera.

b. Menyarankan untuk menambahkan jumlah pemain menjadi tiga pemaindan tiga pemain cadanganyang mana sebelumnya tiga pemain dan satu pemain cadangan terlalu sedikit. Karena jika terjadi cidera terhadap dua pemain maka tim tersebut akan kekurangan pemain.

c. Menyarankan untuk melakukan uji coba terhadap atlet terlatih dan atlet tidak terlatih.

\section{Validasi Ahli Futsal 2 (dua) bersama Bapak April, S.Pd., M.Pd.}

Ahli futsal yang menjadi validator kedua pada penelitian dan pengembangan modifikasi cabang olahraga futsal menjadi futsal mini three on three ini adalah Bapak April, S.Pd., M.Pd. Beliau merupakan salah seorang dosen pengajar pada mata kuliah sepakbola dan peneliti yang berkaitan dengan sepakbola di Fakultas IImu Keolahragaan, Universitas Negeri Padang. Beliau pernah mengikuti Coaching clinik Futsal oleh Pelatih Nasional Vietnam With Sergio Gargelli di Padang pada tahun 2013, beliau juga Pelatih Futsal Putri Mahasiswa Sumatera Barat pada POMNAS di Yogyakarta pada tahun 2013, dan juga beliau Pelatih Futsal Putra Mahasiswa Sumatera Barat pada POMNAS di Sulawesi pada tahun 2017, dan masih banyak prestasi beliau dibidang olahraga futsal maupun olahraga lainnya. Validasi ini dilakukan pada tanggal 25 Juli 2020 dengan cara merekam uji coba produk di lapangan, menampilkan cuplikan rekaman ke validator, mendeskripsikan aturan dan cara kerja produk disertai instrumen penelitian berupa angket.

Tabel 5. Hasil evaluasi permainan futsal mini three on three oleh ahli futsal 2 (dua).

\begin{tabular}{|c|c|c|c|c|c|c|c|}
\hline No & Aspek & Butir Penilaian & SS & $\mathrm{S}$ & KS & TS & STS \\
\hline \multirow{3}{*}{$A$} & \multirow{3}{*}{$\begin{array}{l}\text { Kesesuaian } \\
\text { Permainan }\end{array}$} & $\begin{array}{l}\text { 1. Bentuk, skema, dan sistem } \\
\text { permainan sesuai dengan } \\
\text { kaedah-kaedah olahraga } \\
\text { permainan futsal. }\end{array}$ & & $\checkmark$ & & & \\
\hline & & $\begin{array}{l}\text { 2. Permainan bertujuan untuk } \\
\text { meningkatkan keinginan } \\
\text { masyarakat berolahraga. }\end{array}$ & & $\checkmark$ & & & \\
\hline & & $\begin{array}{l}\text { 3. Permainan bertujuan untuk } \\
\text { menyalurkan kemampuan }\end{array}$ & & $\checkmark$ & & & \\
\hline
\end{tabular}




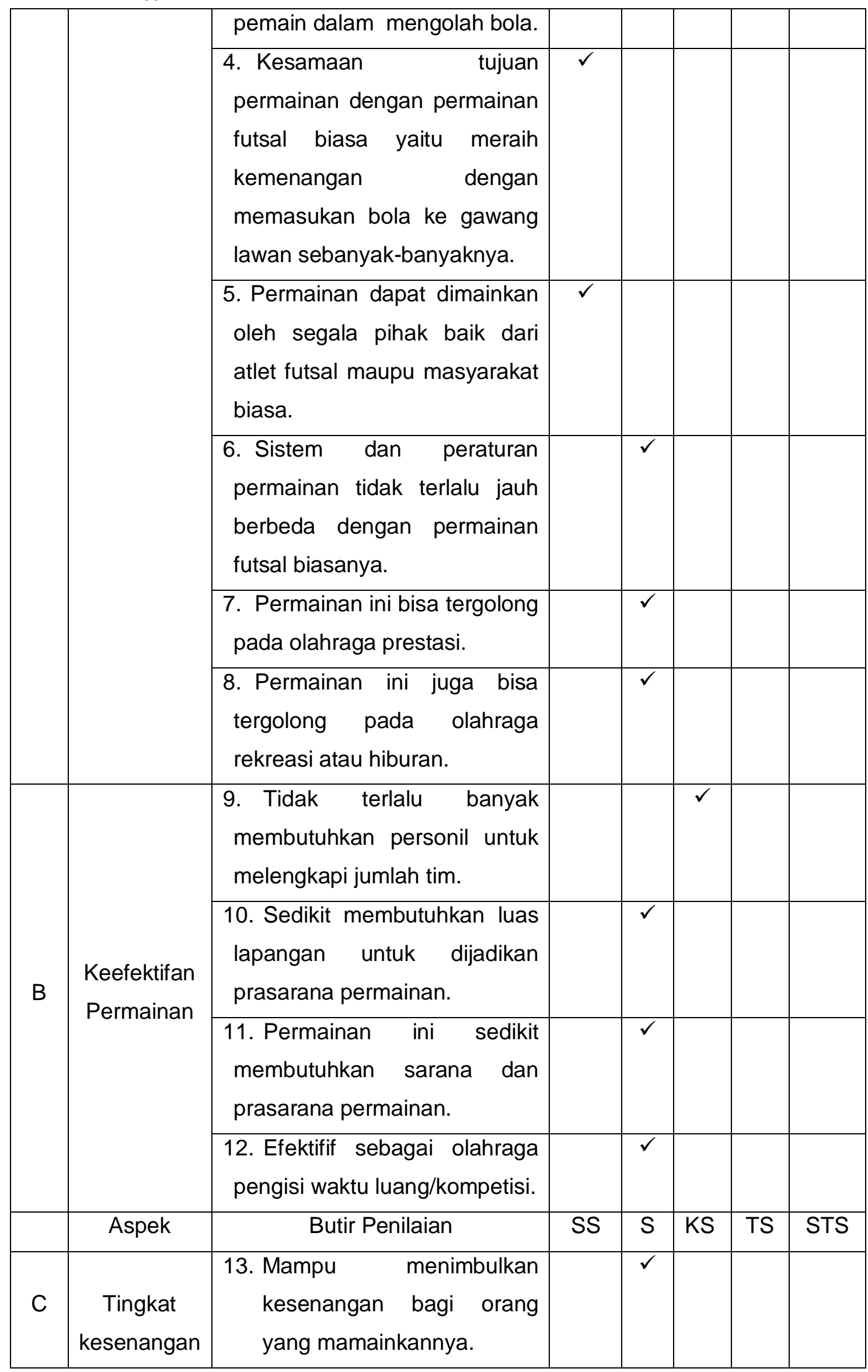


E-ISSN2655-2515

P-ISSN2655-1802

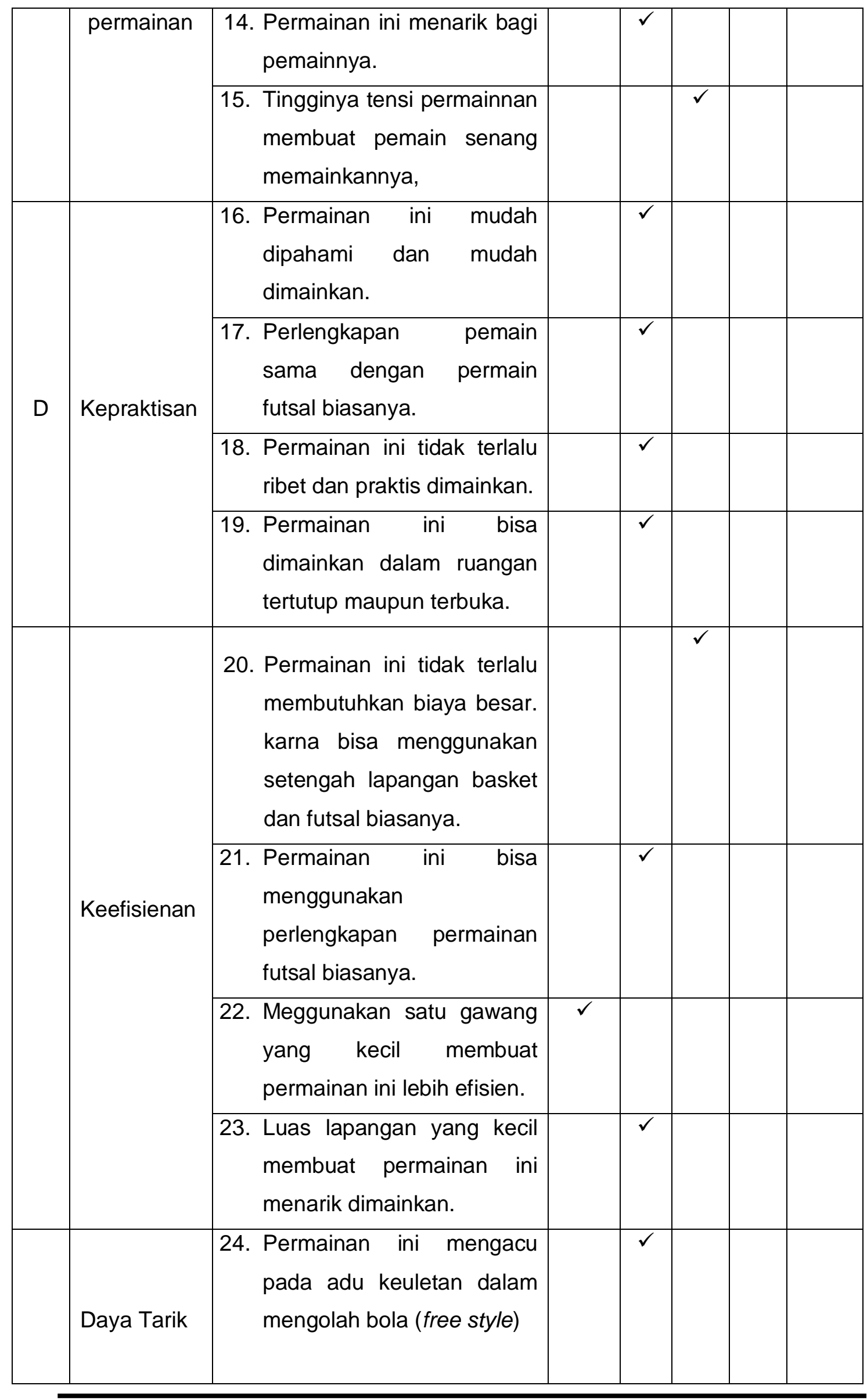




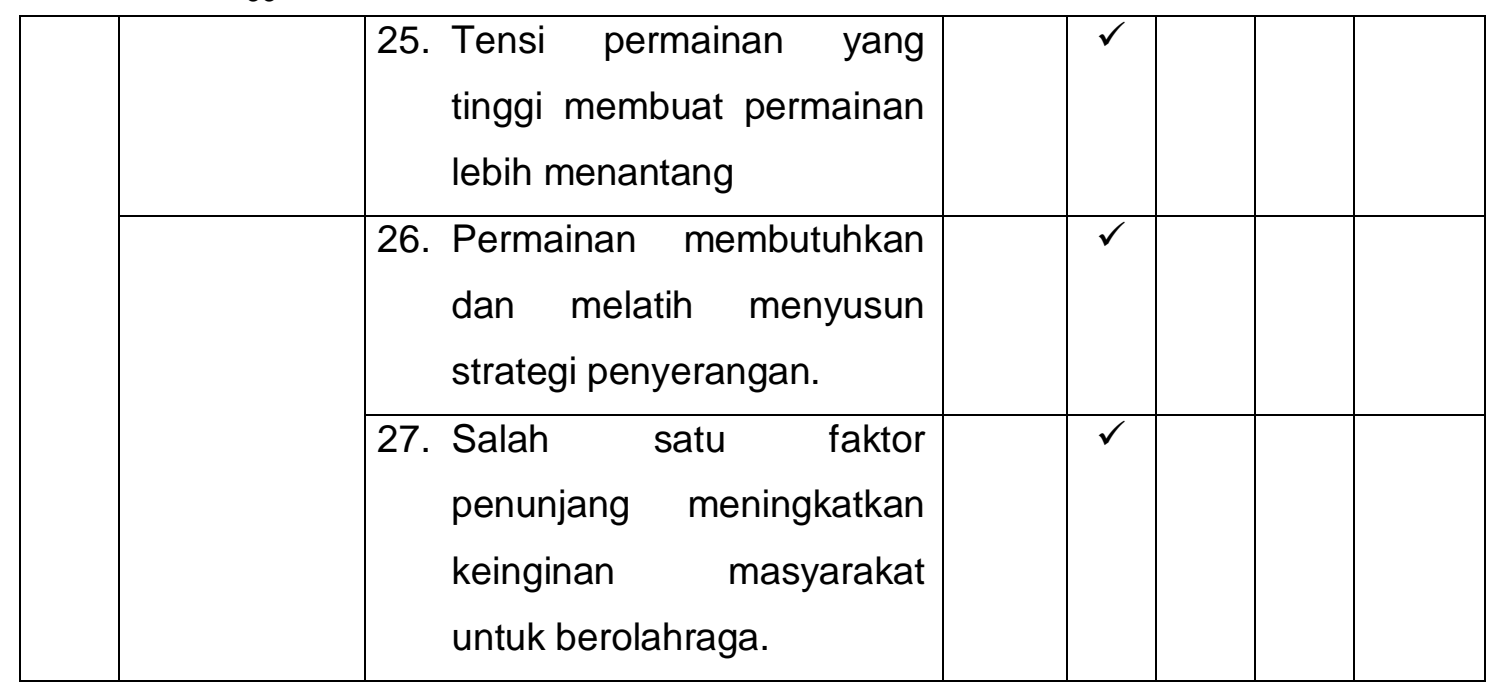

Pada kotak kritik dan saran yang sudah disediakan ahli futsal 2 (dua) mengatakan sangat mendukung untuk terciptanya pengembangan permainan ini. Sehingga ahli memberikan beberapa saran yaitu ditingkatkan kuantitas pemain cadangan mejadi tiga orang dan waktu istirahat antara dua babak menjadi tujuh menit.

Tabel 6.Persentase hasil penilaian permainan futsal mini three on three

\begin{tabular}{|l|c|c|c|c|c|}
\hline NO & Ahli & $f$ & $\mathrm{~N}$ & $(\%)$ & Kategori Kelayakan \\
\hline 1 & Futsal & 108 & 135 & 80 & Baik/Layak \\
\hline
\end{tabular}

Untuk validitas ahli futsal 2 (dua) mendapat persentase penilaian sebesar $80 \%$. Maka dari pada itu dapat diartikan permainan futsal mini three on three ini dapat dikategorikan "Baik/Layak”.

Dalam hal ini validator ahli futsal satu memberikan beberapa saran sebagai pertimbangan yaitu sebagai berikut :

a. Menyarankan pemain cadangan berada di samping lapangan.

b. Menyarankan bagi pemain bertahan yang mendapatkan bola harus mengoper bola kerekan setimnya yang berada di luar garis setengah lingkaran besar atau garis pembatas serangan.

c. Menyarankan untuk menambahkan jumlah pemain cadangan menjadi tiga orang.

d. Validator juga menyarankan untuk mejadikan durasi waktu istirahat antar babak menjadi lima sampai tujuh menit.

Validasi Ahli Futsal 3 (tiga) bersama Bapak Aldo Naza Putra, S.Pd., M.Pd.

Ahli futsal yang menjadi validator ketiga pada penelitian dan pengembangan modifikasi cabang olahraga futsal menjadi futsal mini three on three ini adalah 
E-ISSN2655-2515

P-ISSN2655-1802

Bapak Aldo Naza Putra, S.Pd., M.Pd. Beliau merupakan salah seorang dosen pengajar pada mata kuliah sepakbola dan peneliti yang berkaitan dengan sepakbola di Fakultas IImu Keolahragaan, Universitas Negeri Padang. Beliau telah melewati beberapa pelatihan yang berkaitan dengan sepakbola maupun futsal dalam skala nasional maupun internasional. Diantaranya beliau pernah mengikuti Seminar Internasional The Application Of Sport Science In Football di Jakarta pada tahun 2011, Beliau juga telah mengikuti kursus Licence Futsal Level 1 Nasional di Padang pada tahun 2012, dan juga beliau telah mengikuti Lincence Futsal Level 1 AFC pada tahun 2015. Dan masih banyak prestasi beliau padang cabang olahraga futsal, sepakbola maupun cabang olahraga lainnya.

Validasi ini dilakukan pada tanggal 24 Juli 2020 dengan cara merekam uji coba produk di lapangan, menampilkan cuplikan rekaman ke validator, mendeskripsikan aturan dan cara kerja produk disertai instrumen penelitian berupa angket.

Tabel 7. Hasil evaluasi permainan futsal mini three on three oleh ahli futsal 3 (tiga).

\begin{tabular}{|c|c|c|c|c|c|c|c|}
\hline No & Aspek & Butir Penilaian & SS & $\mathrm{S}$ & KS & TS & STS \\
\hline \multirow{5}{*}{$A$} & \multirow{5}{*}{$\begin{array}{l}\text { Kesesuaian } \\
\text { Permainan }\end{array}$} & $\begin{array}{l}\text { 1. Bentuk, skema, dan sistem } \\
\text { permainan sesuai dengan } \\
\text { kaedah-kaedah olahraga } \\
\text { permainan futsal. }\end{array}$ & $\checkmark$ & & & & \\
\hline & & $\begin{array}{l}\text { 2. Permainan bertujuan untuk } \\
\text { meningkatkan keinginan } \\
\text { masyarakat berolahraga. }\end{array}$ & $\checkmark$ & & & & \\
\hline & & $\begin{array}{l}\text { 3. Permainan bertujuan untuk } \\
\text { menyalurkan kemampuan } \\
\text { pemain dalam mengolah bola. }\end{array}$ & $\checkmark$ & & & & \\
\hline & & $\begin{array}{l}\text { 4. Kesamaan tujuan } \\
\text { permainan dengan permainan } \\
\text { futsal biasa yaitu meraih } \\
\text { kemenangan dengan } \\
\text { memasukan bola ke gawang } \\
\text { lawan sebanyak-banyaknya. }\end{array}$ & $\checkmark$ & & & & \\
\hline & & $\begin{array}{l}\text { 5. Permainan dapat dimainkan } \\
\text { oleh segala pihak baik dari } \\
\text { atlet futsal maupu masyarakat } \\
\text { biasa. }\end{array}$ & $\checkmark$ & & & & \\
\hline
\end{tabular}




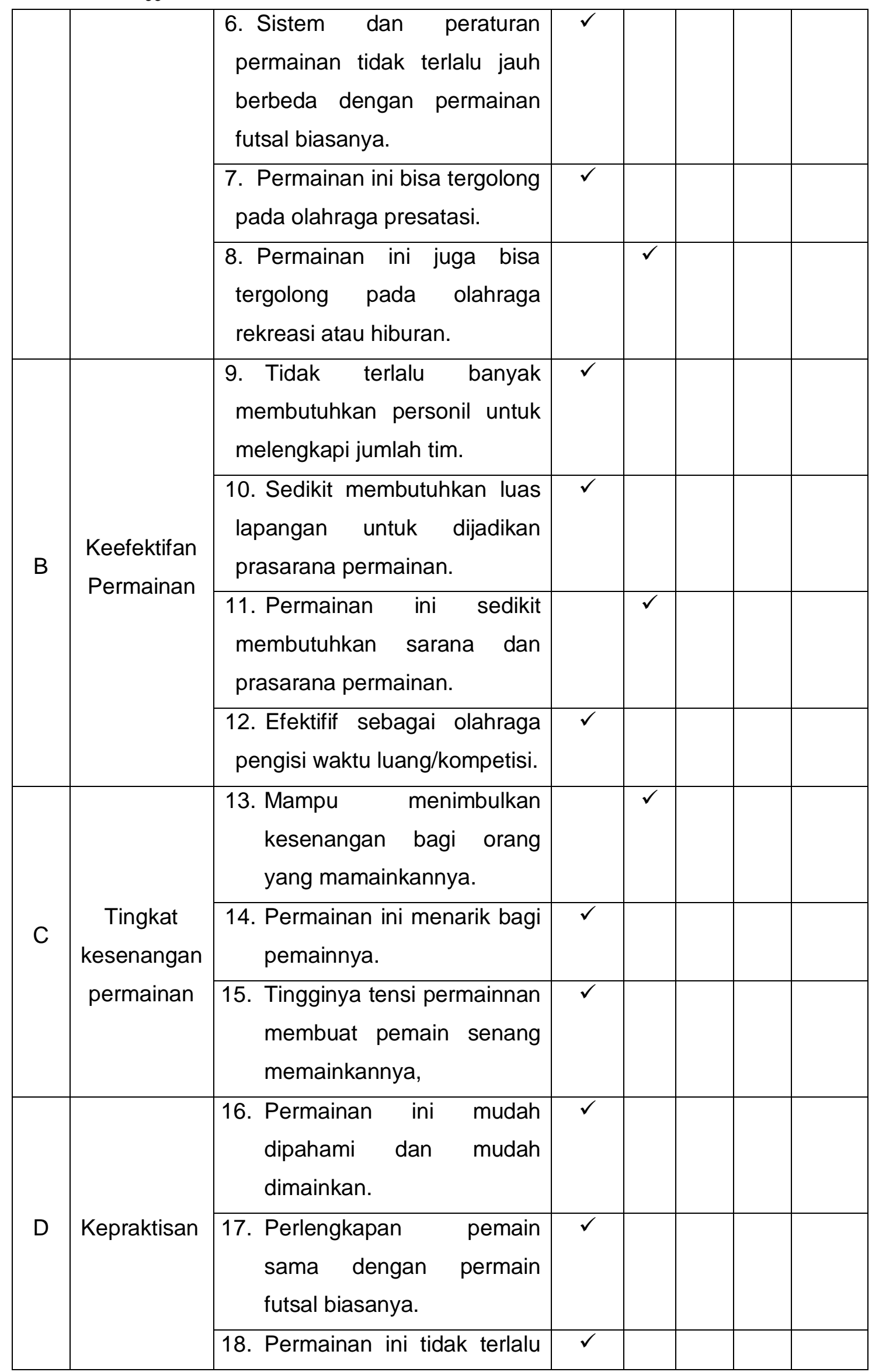




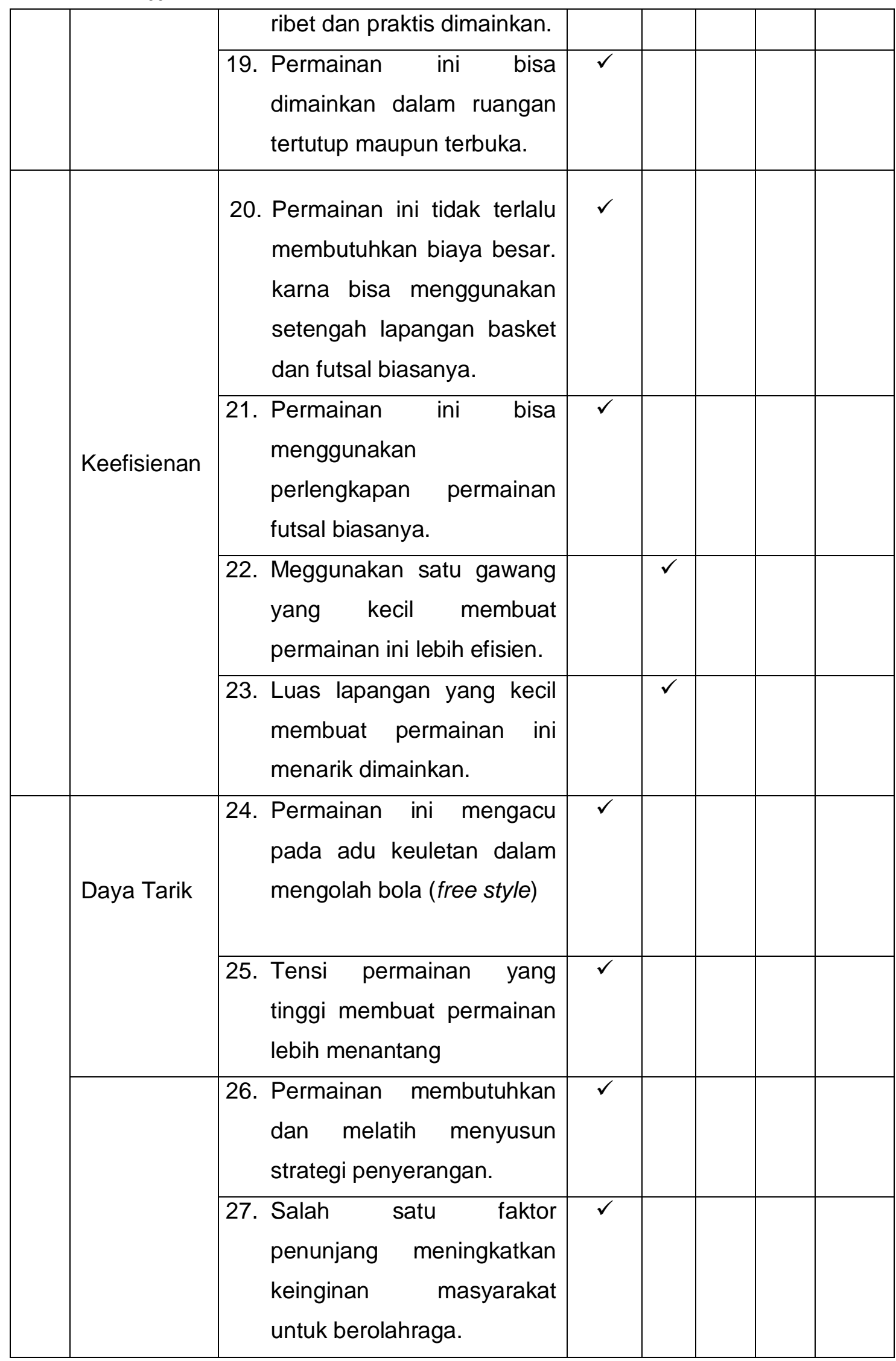

Pada kotak kritik dan saran yang sudah disediakan ahli futsal 3 (tiga) 
E-ISSN2655-2515

P-ISSN2655-1802

mengutarakan sangat mendukung untuk sukses dan terciptanya pengembangan permainan ini. Sehingga ahli memberikan beberapa saran yaitu ditingkatkan kuantitas pemain cadangan mejadi tiga orang karena permainan dengan tensi tinggi mengakibatkan pemain terlalu kelelahan dan tingginya resiko terjadinya cidera.

Tabel 8.Persentase hasil penilaian permainan futsal mini three on three

\begin{tabular}{|l|c|c|c|c|c|}
\hline NO & Ahli & $f$ & $\mathrm{~N}$ & $(\%)$ & Kategori Kelayakan \\
\hline 1 & Futsal & 130 & 135 & 96,29 & Sangat Baik/Layak \\
\hline
\end{tabular}

Untuk validitas ahli futsal 3 (tiga) mendapat persentase penilaian sebesar $96,29 \%$. Maka dari pada itu dapat diartikan permainan futsal mini three on three ini dapat dikategorikan "Sangat Baik/Layak".

Dalam hal ini validator ahli futsal satu memberikan beberapa saran sebagai pertimbangan yaitu sebagai berikut :

a. Menyarankan untuk menambah jumlah pemain cadangan

b. Validator juga menyarankan untuk mengurangi durasi waktu istirahat antar babak mejadi lima menit.

Penelitian pengembangan ini bertujuan untuk mengetahui bagaimana kelayakan sebuah produk yang bernama permaian futsal mini three on three.Penelitian ini diuji cobakan terhadap pemain pada club futsal PS Putra pauh Kambar dengan sampel uji coba skala kecil delapan orang dan uji coba skala besar sebanyak 12 orang. Uci coba permainan ini dilakukan lapangan yang barnama Berkah Futsal yang beralamat di Kecamatan Sintoga Kabupaten Padang Pariaman, Provinsi Sumatera Barat.

Dalam prosesnya penelitan dan pengembangan ini melewati langkah-langkah yang terdapat dalam metode penelitian Research and Development (RND) yaitu potensi masalah, pengumpulkan data, desain produk, validasi desain, revisi desain, dan uji coba produk. Uji coba skala kecil dilakukan pada tanggal 15 Juli 2020 dengan jumlah sampel delapan orang pemain dan uji coba skala besar dilakukan pada tanggal 15 Agustus 2020 dengan jumlah sampel 12 orang pemain. Futsal mini three on three ini divalidasi oleh tiga ahli futsal yang mengajar Fakultas IImu Keolahragaan Universitas Negeri Padang. Dari proses validasi tiga ahli futsal tersebut maka hasil dari ahli futsal satu mendapatkan kategori Sangat Baik/Layak dengan persentase $90.37 \%$, ahli futsal dua mengkategorikan Baik/Layak dengan persentase $80 \%$, dan ahli futsal tiga 
mendapatkan kategori Sangat Baik/Layak dengan persentase 96.29\%. Hal ini menunjukan bahwasanya permain futsal mini three on three ini Sangat Baik/Layak dan bisa dimainkan oleh segala pihak.

\section{Kesimpulan}

Penelitian pengembangan ini menghasilkan sebuah produk yaitu sebuah cabang olahraga baru yang bernama Futsal Mini Three on Three.Pada penelitian ini terdapat tiga orang ahli futsal sebagai validator permainan ini.maka dari itu dari hasil evaluasi serta penilaian dari ketiga ahli tersebut mendapatkan persentase kelayakan sebesar 90,37\%, 80\% dan 96,29\%. Maka hasil dari penelitian berupa permainan Futsal Mini Three on Three ini dikategorikan "Sangat Baik/Layak". Permainan ini dapat dimainkan oleh berbagai kalangan, baik dari pemain futsal profesional maupun masyarakat awam, baik dari masyarkat perdesaan maupun oleh masyarakat perkotaan.

\section{Saran}

Berdasarkan kesimpulan yang dikemukakan di atas, maka penelti dapat memberikansaran diantaranya sebagai berikut:

1. Bagi masyarakat yang ingin memainkan permainan ini harap dibaca terlebih dahulu panduan dan aturan permainan futsal mini three on three ini.

2. Bagi pihak dosen maupun instasi-instasi yang berkaitan dengan keolahragaan agar dapat mensosialisasikan permainan ini agar permainan ini dapat dikenal masyarakat baik dari masyarakat daerah, nasional maupun internasional.

3. Bagi mahasiswa seluruh Indonesia terkusus mahasiswa dari jurusan Kesehatan dan Rekreasi Fakultas IImu Keolahragaan Universitas Negeri Padang agar tetap berprestasi dan berkreasi dibidang olahraga bertujuan memajukan olahraga Indonesia.

4. Bagi segala kalangan untuk mencoba dan mensosialisasikan permainan ini agar dapat berkembang dengan baik.

5. Untuk organiasi-organisasi kampus agar ikut serta dalam mensosialisasikan permainan ini melalui kegiatan-kegiatan yang dilakukan seperti halnya kegiatan rutin tahunan kampus POMFIK UNP.

\section{DAFTAR PUSTAKA}

Narlan, Abdul.Dicky T. Juniar.Dkk. 2017. Pengembangan Instrumen Keterampilan Olahraga Futsal. Jurnal siliwaangi (Volume 3.No.2, 2017 Seri pendidikan). HIm. $241-247$.

Rahmanda, Andri T. dan Anton Komaini. 2018. Evaluation Of The Futsal Athlete 
Training Program In The City Sawahlunto. Jurnal Stamina (Volume 1, Nomor 1, Desember 2018). HIm. 145-153.

Setiyawan.2017. Visi Pendidikan Jasmani dan Olahraga.Jurnal Ilmiah Penjas,, ISSN :2442-3874 (Volume 3, No. 1, January 2017). HIm. 74 - 86.

Sugiyono, 2012. Metode Penelitian Administrasi. Bandung: Alfabeta.

Sutanto, Teguh. 2019. Buku Pintar Olahraga. Yogyakarta: Pustaka Baru Press.

Undang-Undang RI Nomor 3 Tahun (2005).Pembinaan dan Pengembangan Olahraga. 